Summer 6-28-2018

Is Guardian Permission a Barrier to Online Sexual Health Research Among Adolescent Males Interested in Sex With Males?

Kimberly Nelson

Michael P. Carey

Celia B. Fisher

Follow this and additional works at: https://research.library.fordham.edu/psych_facultypubs

Part of the Psychology Commons 


\title{
Is Guardian Permission a Barrier to Online Sexual Health Research Among Adolescent Males Interested in Sex With Males?
}

\author{
Kimberly M. Nelson, Michael P. Carey \& Celia B. Fisher
}

To cite this article: Kimberly M. Nelson, Michael P. Carey \& Celia B. Fisher (2018): Is Guardian Permission a Barrier to Online Sexual Health Research Among Adolescent Males Interested in Sex With Males?, The Journal of Sex Research, DOI: 10.1080/00224499.2018.1481920

To link to this article: https://doi.org/10.1080/00224499.2018.1481920

曲 Published online: 28 Jun 2018.

Submit your article to this journal ๘

View Crossmark data $₫$ 


\title{
Is Guardian Permission a Barrier to Online Sexual Health Research Among Adolescent Males Interested in Sex With Males?
}

\author{
Kimberly M. Nelson \\ Centers for Behavioral and Preventive Medicine, The Miriam Hospital, and Department of \\ Psychiatry and Human Behavior, Brown University
}

Michael P. Carey

Centers for Behavioral and Preventive Medicine, The Miriam Hospital, Department of Psychiatry and Human Behavior, Brown University and Department of Behavioral and Social Sciences, Brown University

\author{
Celia B. Fisher \\ Department of Psychology, Center for Ethics Education, Fordham University
}

\begin{abstract}
Institutional review boards (IRBs) that refuse to grant waivers of guardian permission may hinder research to inform needed online sexual health interventions for adolescent males interested in sex with males (AMSM). Information on the challenges of obtaining (or waiving) guardian permission is imperative. In June and July 2017, AMSM (N = 206; ages 14 to 17) in the United States completed an online survey on sexual behaviors, sexually explicit media use, and sexual education exposure/needs. A mixed-methods approach assessed attitudes toward guardian permission for the current survey and future online sexual health intervention research. Logistic regression models assessed differences by "outness" to a guardian. A framework matrix analysis was conducted to summarize, then aggregate, qualitative responses. Findings indicated that most AMSM would not participate if guardian permission was required (current: 83\%; future: $87 \%$ ). Youth who were not out were more likely to say they would not participate (current: adjusted odds ratio $[A O R]=2.8$, 95\% confidence interval [CI]: 1.2 to 6.8); future: AOR $=4.7,95 \%$ CI: 1.6 to 13.5). Participants reported that guardian permission would be an invasion of their privacy, lead to involuntary outing, and endanger participants. Overall, guardian permission appears to be a barrier to AMSM participation in online sexual health research. Investigators and IRBs should consider alternative practices and policies to facilitate such research.
\end{abstract}

Adolescent males interested in sex with males (AMSM) are at elevated risk for human immunodeficiency virus (HIV) in the United States, accounting for $93 \%$ of new infections among males in their age cohort (Centers for Disease Control and Prevention [CDC], 2016). Racial/ethnic minority AMSM are particularly vulnerable (CDC 2016). HIV infection among AMSM often results from early sexual experiences (Kann et al., 2016) or occurs later as a result of behavior patterns established during adolescence (Glick \& Golden, 2014; Kann et al., 2016). Sexual education interventions that serve AMSM, preferably before sexual behavior patterns are formed, are essential to addressing HIV disparities among these youth.

Correspondence should be addressed to Kimberly M. Nelson, Centers for Behavioral and Preventive Medicine, The Miriam Hospital, Coro West, Suite 309, 164 Summit Ave, Providence, RI 02906. E-mail: kimberly_nelson_1@brown.edu
Despite the need, there is a dearth of educational resources to prepare AMSM for healthy sexual activity. AMSM are less likely than their heterosexual peers to receive relevant sexual health information in school (Raifman, Beyrer, \& Arrington-Sanders, 2018; Rasberry et al., 2018) or from their parents (Mustanski, Greene, Ryan, \& Whitton, 2015). As a result, AMSM turn to the Internet, where they obtain sexual health information and make connections with other AMSM (Mustanski, Lyons, \& Garcia, 2011). AMSM use sexually explicit online media (SEOM) to learn the mechanics of sex, confirm their sexual attractions, and learn about gay culture (Arrington-Sanders et al., 2015; Kubicek, Beyer, Weiss, Iverson, \& Kipke, 2010). Because the Internet is particularly influential on the sexual development of AMSM, and because it can be an effective way to reach hidden populations in research (Lane, Armin, \& Gordon, 2015), the 
Internet is an ideal location to provide sexual health interventions to AMSM.

Limited research has investigated the Internet's potential to provide sexual health interventions to AMSM (Hergenrather, Emmanuel, Durant, \& Rhodes, 2016; Ybarra et al., 2017). One barrier to such research is the reluctance of institutional review boards (IRBs) to approve waivers of guardian permission. This issue was first raised by Mustanski (2011), as was a call for research in this area. Subsequent research has documented guardian permission as a potential barrier to sexual and gender minority youth participation in online sexuality survey research (Macapagal, Coventry, Arbeit, Fisher, \& Mustanski, 2017), HIV testing studies (Mustanski, Coventry, Macapagal, Arbeit, \& Fisher, 2017), and pre-exposure prophylaxis (PrEP) prevention trials (Fisher, Arbeit, Dumont, Macapagal, \& Mustanski, 2016). This research indicates that for these types of studies requiring guardian consent is likely to decrease participation rates and create a biased sample; it could also lead to harm for the participants (Fisher et al., 2016; Macapagal et al., 2017; Mustanski, Coventry, et al., 2017). This is particularly true for sexual and gender minority youth who are not yet out to their guardians (Fisher et al., 2016; Macapagal et al., 2017; Mustanski, Coventry, et al., 2017). For these reasons, guardian consent waivers have been recommended by research ethics experts (Fisher \& Mustanski, 2014; Mustanski \& Fisher, 2016).

Regardless of expert recommendations, IRBs often fail to consider AMSM-unique risks related to requiring guardian permission (Fisher \& Mustanski, 2014; Mustanski \& Fisher, 2016). When IRBs decline to approve waivers of guardian permission, they inadvertently hinder research that could form the evidential base for sexual health interventions for AMSM. The current study sought to provide IRBs and investigators with the information needed to make informed decisions around guardian permission for AMSM participation in online sexual health research, specifically with regard to AMSM's willingness to participate in online sexual health interventions designed to increase youth's ability to engage in health sexual relationships with male partners and decrease their HIV risk. We used mixedmethods to determine the extent to which guardian permission is a barrier to engagement in online sexual intervention research among AMSM, particularly for AMSM who are not out to their guardians.

This study builds on and extends previous research in this area (Fisher et al., 2016; Macapagal et al., 2017; Mustanski, Coventry, et al., 2017) in multiple ways. Previous studies included sexual and gender minority youth more broadly and had relatively small samples of AMSM (range of AMSM in previous studies: $n=22$ to 29). Our study represents the largest study to date $(N=206)$ of AMSM-specific attitudes toward guardian permission for sexual health research. Further, previous studies focused on sexual and gender minority youth attitudes toward guardian permission for an online survey about sexual health and sexual/gender minority identity (Macapagal et al., 2017), an HIV testing study (Mustanski, Coventry, et al., 2017), and a PrEP adherence trial (Fisher et al., 2016). Our study is the first to assess AMSM-specific attitudes toward guardian permission for online sexual health intervention research. Although guardian permission may serve as a barrier to sexual and gender minority youth participation in sexual health research generally, AMSM represent a unique population that experiences substantial sexual health disparities in the United States and is in need of targeted online sexual health interventions. Given this need, information on the challenges of obtaining (or waiving) guardian permission for this specific research is imperative.

\section{Method}

\section{Study Design}

Closed and open-ended questions were imbedded in a cross-sectional survey designed to inform the development of an online-administered sexual health intervention for AMSM (ages 14 to 17). Participants were recruited in June and July 2017 via online advertisements and posts on social media sites (e.g., Instagram). Social media advertisements/posts included GIFs and static images that featured young men and emoji. Text focused on participating in an online survey to help researchers develop a more inclusive online sexual health program. To optimize racial/ethnic diversity and increase the potential that advertisements/ posts would be seen by males who are interested in male sexual partners, but not necessarily identify as gay/bisexual, advertisements/posts were broadly targeted to 14- to 17year-old males in the United States who were identified by the Facebook/Instagram algorithms as interested in topics our youth advisory board and our own research generated as popular among racial/ethnic minority AMSM (e.g., King Bach, Kim Kardashian, RuPaul's Drag Race, Todrick Hall, Shakira, Rihanna). Eligibility criteria were (1) age 14 to 17 ; (2) cisgender male; (3) self-identify as gay/bisexual, report being sexually attracted to males, or report having voluntary sexual contact with a male partner (past year); (4) reside in the United States; (5) have a personal e-mail address; and (6) be new to the study.

Upon clicking on an advertisement or social media post, potential participants were directed to the survey Web site, hosted using REDCap (Harris et al., 2009), which described the study and asked respondents to continue for eligibility questions. To protect against fraudulent entries or multiple enrollments, screening and survey responses were crossreferenced against date of birth, location, sexual activity, and e-mail address (Bowen, Daniel, Williams, \& Baird, 2008; Sullivan, Grey, \& Simon Rosser, 2013).

After screening, respondents progressed to consent material. We adapted procedures used by Newcomb \& Mustanski (2014); thus, capacity to consent was confirmed via four questions that evaluated respondents' ability (1) to name things they would be expected to do during the study, (2) to explain what they would do if they no longer wished to participate in the study, (3) to explain what they would do if they experienced distress during the study, and (4) to identify potential risks for participating in 
the study (Dunn \& Jeste, 2001; Newcomb \& Mustanski, 2014; The University of California at San Diego Task Force on Decisional Capacity, 2003). Specifically, participants were asked: (1) "If you agree to be in this study, what are we asking you to do?" (2) "What should you do if you no longer want to be in this study?" (3) "What can you do if you experience distress while taking part in this study?" and (4) "What are the potential risks of being in this study?" Respondents unable to answer all four questions after three tries were ineligible. Those who consented received an e-mail containing a unique survey link. The survey took 30 minutes $(S D=12)$ on average. Participants who completed the survey received a $\$ 15$ Amazon.com gift code by e-mail. All procedures, including a waiver of guardian consent, were reviewed and approved by our hospital IRB.

\section{Measures}

The survey covered multiple potentially sensitive topics (e.g., sexual behaviors, SEOM use, and sexual education exposure/needs) in addition to questions about guardians and ethical issues. For this article, we report on sociodemographics, outness to guardians, and attitudes toward guardian permission.

Sociodemographics. Characteristics included recruitment source (Instagram, Facebook/Other), census region of the United States (Northeast, Midwest, South, West), age (continuous), race/ethnicity (White, Black/African American, Latino, mixed race/other), enrollment in school (yes, no), highest education level $(<9$ th grade, 9th, 10th, 11th grade or more), living situation (in guardian's home, other), urbanicity (metropolitan residence, other; University of North Dakota Center for Rural Health, 2014) employment (unemployed, employed at least part time), sexual orientation (gay identified, other), and age realized sexually attracted to men (continuous). "Other" in recruitment source includes from a friend $(n=11)$ or participants who reported "other" as their source $(n=3)$. Census region was designated using self-reported state of residence (U. S. Department of Commerce Economics and Statistics Administration, 2015).

Guardians. Participants indicated whether they had told their guardian(s) that they were sexually attracted to other boys/males (yes, no) (Glick \& Golden, 2014). Separate questions assessing primary and secondary guardian (if they had one) were combined to form a variable indicating whether they were out with at least one guardian $(0,1)$.

Attitudes toward guardian permission. Guardian permission questions were adapted from previous work (Fisher et al., 2016). At the end of the survey, participants rated if (a) they would have participated in the current survey if a guardian's permission had been required (yes, no), (b) researchers should require a guardian's permission for this type of survey (yes, no), and (c) they agreed (4-point Likert scale) with reasons why researchers should (e.g.,
"They could help explain the risks and benefits to me") or should not (e.g., "They might punish me") require guardian permission. Other reasons researchers should and should not get written guardian permission for this type of survey were assessed in an open-ended format.

Participants then read the following description of a future study involving an online sexual health intervention:

The next set of questions asks about how you might feel about getting written parental/guardian permission for the study of the online sexual health program we are designing. Participants will be asked to fill out a survey, complete the developed sexual health program or use an alternative source of online sexual health information, and then fill out two additional surveys (one right after they complete the intervention and one 3 months later). The surveys will contain information similar to what you just filled out. The sexual health program will take about 90 minutes to complete and will include a discussion of online pornography.

Participants were then asked questions that mirrored the questions and response options they answered about the current survey (described in the previous section; i.e., would they participate, should guardian permission be required, reasons to require guardian permission, reasons against requiring guardian permission, and open-ended options for and against guardian permission).

\section{Analyses}

Quantitative analysis. Sociodemographic differences by outness with a guardian were assessed using $t$ and $\chi^{2}$ tests. Logistic regression models assessed differences in attitudes toward guardian permission by outness with a guardian. Race/ethnicity, age, and sexual orientation were controlled for in adjusted multivariable logistic regression models. Of the 206 AMSM, 34 (17\%) had missing data on one or more guardian permission attitude variables. To assess sociodemographic differences between participants with missing data versus those with complete data, we conducted $t$ and $\chi^{2}$ tests. Participants with missing data were more likely to live outside a metropolitan area ( $31 \%$ versus $14 \%, p=0.03$ ). There were no other sociodemographic differences.

Qualitative analysis. Two coders from the study team independently reviewed answers to the four open-ended questions (i.e., other reasons to require guardian permission for the current survey; other reasons against requiring guardian permission for the current survey; other reasons to require guardian permission for the future intervention study; other reasons against requiring guardian permission for the future intervention study) and identified emergent concepts. The coders agreed upon a set of initial codes, which included deductive codes drawn from research questions (e.g., guardians could provide help with the logistics of participation) and inductive codes representing concepts raised in participant answers (e.g., participants feel capable of consenting themselves). The codebook was revised 
throughout. Data from the open-ended questions were doublecoded and disagreements were resolved through discussions between the coders.

Finalized codes, and the answers assigned to them, were entered into NVivo 11 (NVivo Qualitative Data Analysis Software, 2012). Cohen's kappa for the final codes ranged from 0.83 to 1.00 , indicating excellent interrater reliability (McHugh, 2012). A framework matrix analysis was conducted to summarize, aggregate, and establish frequencies of code endorsement (Green \& Thorogood, 2013). A mixedmethods analysis was conducted to explore whether endorsement of codes differed according to whether participants had disclosed their sexual attraction to male partners (i.e., were out) to their guardians. In accordance with prior studies (Magee, Bigelow, Dehaan, \& Mustanski, 2012; Mustanski, Coventry, et al., 2017), we performed these analyses only on codes endorsed by at least five participants and considered differences by outness in code application rates of at least $20 \%$ to be meaningful.

To assess sociodemographic differences between participants who responded to open-ended questions versus those who did not, we conducted $t$ and $\chi^{2}$ tests. Most participants $(n=122,59 \%)$ answered at least one of the open-ended questions. Participants recruited through Facebook/Other were more likely to have answered at least one of the open-ended questions compared to those recruited through Instagram $\left(76 \%\right.$ versus $\left.56 \%, \chi^{2}=4.4, p=0.04\right)$. There were no other sociodemographic differences.

\section{Results}

\section{Participants}

A total of 2,346 potential participants clicked on the survey link. Of these, 2,232 (95\%) agreed to the screener and $661(30 \%)$ were eligible (see Figure 1). About half of the eligible respondents $(n=353 ; 53 \%)$ completed the consent process, agreed to participate, and were e-mailed the survey. Of these, $287(81 \%)$ completed the survey. A total of 80 (28\%) participants were excluded due to internal discrepancies suggesting ineligibility or a potential duplicate. One $(0.3 \%)$ participant had missing data about outness with a guardian. This left a final analytic sample of 206 AMSM.

There were two steps in the process where there were differences in attrition by sociodemographics collected in the screener (age, race/ethnicity, sexual orientation). First, those who identified as gay were more likely to attempt the capacity to consent questions compared to those who did not $\left(80 \%\right.$ versus $\left.73 \%, \chi^{2}=4.6, p=0.02\right)$. Second, mixed race/other individuals were more likely to establish capacity to consent compared to White, Black/African American, and Latino individuals (White: $78 \%$ versus Black/African American: $82 \%$ versus Latino: $72 \%$ versus mixed race/ other: $\left.90 \%, \chi^{2}=8.3, p=0.04\right)$. There were no other sociodemographic differences in attrition.
The average age of participants was 16 years $(S D=1.0)$ and half $(53 \%)$ were out to one or more guardians (see Table 1). The majority (84\%) were recruited via Instagram. Participants reported living in 40 states (17\% Northeast, $20 \%$ Midwest, $29 \%$ South, and $34 \%$ West). Approximately half (48\%) identified as racial/ethnic minorities, almost all $(95 \%)$ were enrolled in school, most (93\%) lived at home with their parents/guardians, and the majority (87\%) lived in a metropolitan area. Two-thirds (66\%) self-identified as gay. Participants who were out with at least one guardian were more likely to be enrolled in school ( $98 \%$ versus $92 \%, p=0.03)$ and gay identified $(74 \%$ versus $56 \%, p<0.01)$. There were no other sociodemographic differences by outness.

\section{Participation if Guardian Permission Is Required}

Most AMSM would not participate in either the current survey or the future study if guardian permission was required (current: 83\%; future: $87 \%$; see Table 2). Compared to youth who were out to one or more guardians, youth who were not out had almost three times greater odds of reporting that they would not participate in the current survey (adjusted odds ratio $[\mathrm{AOR}]=2.9$, 95\% confidence interval [CI]: 1.2 to 6.8 ) and approximately five times greater odds of reporting that they would not participate in the future intervention study (AOR $=4.8,95 \%$ CI: 1.7 to 13.9$)$ if guardian permission was required. Regardless of outness, almost all participants felt that guardian permission should not be required (current: $94 \%$; future: $98 \%$ ).

\section{Reasons to Require Guardian Permission}

Quantitative data. Half of the AMSM agreed with the investigator-nominated reasons that guardian permission should be required for the current survey (range: $43 \%$ to $54 \%$ ) or future study (range: $44 \%$ to $54 \%$; see Table 3 ). The only differences by outness in agreement with these reasons was that guardian permission provided opportunities for parents to explain research risks and benefits for the current survey. AMSM who were not out were less likely to agree with this reason $(\mathrm{AOR}=0.5,95 \% \mathrm{CI}: 0.3$ to 0.9$)$.

Qualitative data. Of those who responded to the open-ended question regarding the current survey $(n=91)$ or the future study $(n=56)$, one of the most frequently endorsed reasons for why guardian permission should be required was that guardians could support youth as they participated (current: 24\%; future: $32 \%$ ). For example, one participant noted, "My Papa could help me understand questions after survey" (15 years old, Latino, out with a guardian). Another participant wrote, "They could help me if I was unsure what I was thinking" (17 years old, Black/ African American, out with a guardian); another stated, "They could go through it with me" (14 years old, Black/ African American, not out with a guardian). There was not a 


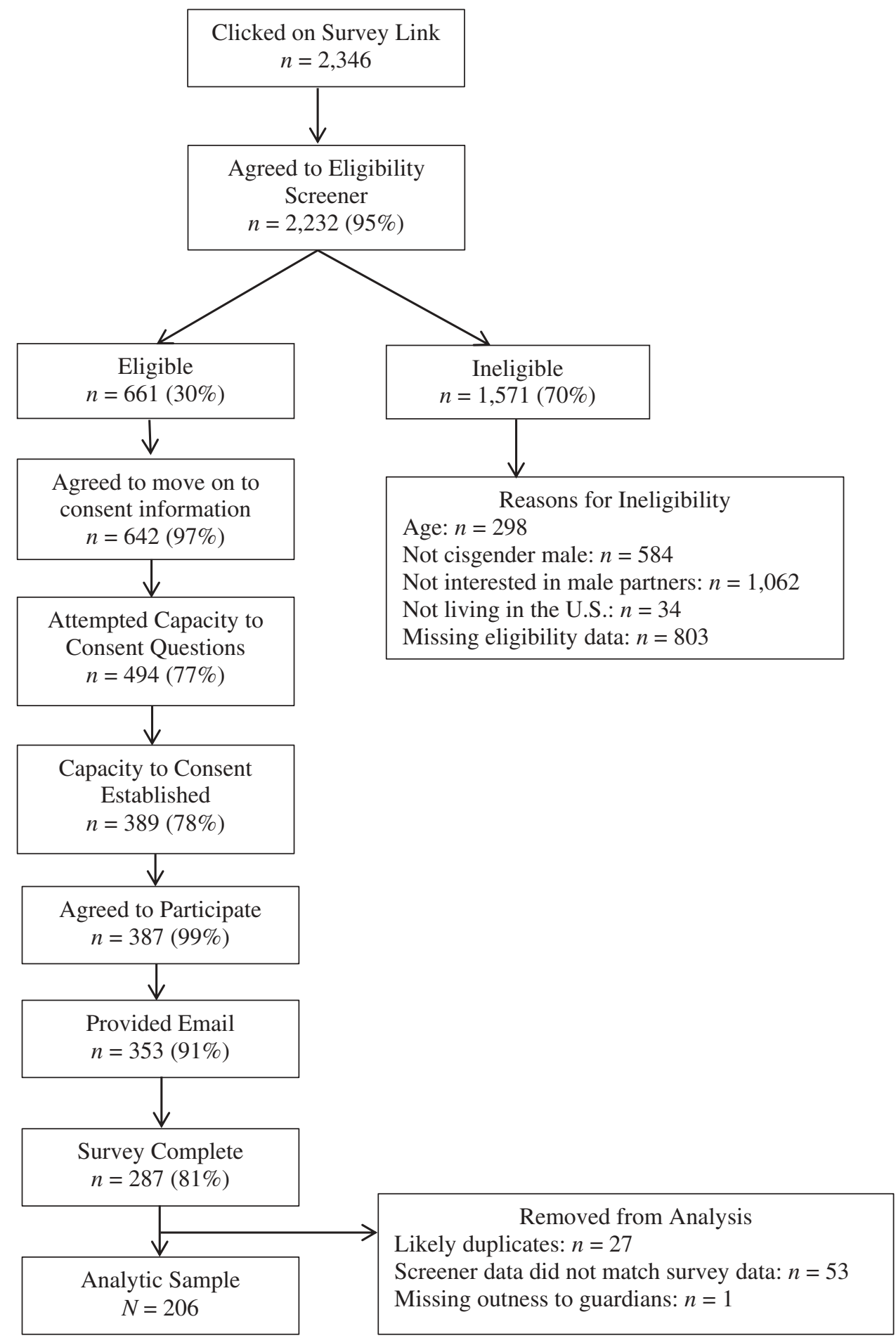

Figure 1. Study flow diagram.

meaningful difference in the frequency of endorsement of this potential benefit between those who were out compared to those who were not out with a guardian (current: $33 \%$ versus $15 \%$; future: $41 \%$ versus $22 \%$ ).

Interestingly, in response to this question, many participants took this opportunity to voice their opposition to the assertion that parental permission should be required (current: 36\%; future: 27\%). The majority of these responses simply stated, as one participant did, "They shouldn't" (15 years old, mixed race/other, out with a guardian). Some participants were specific about reasons why guardian permission should not be required. For example, one stated, "It's uncomfortable and I would lie on the survey if parental consent was required" (15 years old, White, out 
Table 1. Sociodemographics by Outness With at Least One Guardian Among 14- to 17-Year-Old Males Who Are Interested in Male Sexual Partners in the United States

\begin{tabular}{|c|c|c|c|c|}
\hline \multirow[b]{3}{*}{ Sociodemographics } & \multirow{3}{*}{$\frac{\frac{\text { Total }}{(N=206)}}{n(\%)}$} & \multirow{3}{*}{$\frac{\frac{\text { Not Out }}{(n=97)}}{n(\%)}$} & \multirow{3}{*}{$\frac{\frac{\text { Out }}{(n=109)}}{n(\%)}$} & \multirow[b]{3}{*}{$\chi^{2}$} \\
\hline & & & & \\
\hline & & & & \\
\hline \multicolumn{4}{|l|}{ Recruitment source } & 0.9 \\
\hline Instagram & $173(84)$ & $79(81)$ & $94(86)$ & \\
\hline Facebook/Other & $33(16)$ & $18(18)$ & $15(14)$ & \\
\hline \multicolumn{4}{|l|}{ Region } & 1.2 \\
\hline Northeast & $34(17)$ & $16(17)$ & $18(17)$ & \\
\hline Midwest & $41(20)$ & $17(18)$ & $24(23)$ & \\
\hline South & $58(29)$ & $28(29)$ & $30(29)$ & \\
\hline West & $69(34)$ & $36(37)$ & $33(31)$ & \\
\hline \multicolumn{4}{|l|}{ Age (in years) } & 4.6 \\
\hline 14 & $32(16)$ & $18(19)$ & $14(13)$ & \\
\hline 15 & $51(25)$ & $23(24)$ & $28(26)$ & \\
\hline 16 & $68(33)$ & $36(37)$ & $32(29)$ & \\
\hline 17 & $55(27)$ & $20(21)$ & $35(32)$ & \\
\hline \multicolumn{4}{|l|}{ Race/ethnicity } & 4.6 \\
\hline White & $107(52)$ & $52(54)$ & $55(51)$ & \\
\hline Black/African American & $30(15)$ & $17(18)$ & $13(12)$ & \\
\hline Latino & $42(20)$ & $14(14)$ & $28(26)$ & \\
\hline Mixed race/other & $25(12)$ & $13(14)$ & $12(11)$ & \\
\hline Currently enrolled in school & $196(95)$ & $89(92)$ & $106(98)$ & $4.5^{*}$ \\
\hline \multicolumn{4}{|l|}{ Highest level of education achieved } & 2.1 \\
\hline Less than 9th grade & $26(13)$ & $13(14)$ & $13(12)$ & \\
\hline 9th grade & $49(24)$ & $27(28)$ & $22(21)$ & \\
\hline 10th grade & $51(26)$ & $24(25)$ & $27(26)$ & \\
\hline 11th grade or more & 74 (37) & $31(33)$ & $43(41)$ & \\
\hline Live in guardian's/guardians' home & $191(93)$ & $87(90)$ & $104(95)$ & 2.5 \\
\hline Metropolitan residence & $169(87)$ & $79(87)$ & $90(87)$ & 0.0 \\
\hline Ever been homeless & $12(6)$ & $8(8)$ & $4(4)$ & 2.0 \\
\hline Employed at least part time & $71(34)$ & $30(31)$ & $41(38)$ & 1.0 \\
\hline \multirow[t]{2}{*}{ Gay identified } & $136(66)$ & $54(56)$ & $82(75)$ & $8.8^{* *}$ \\
\hline & $M(S D)$ & $M(S D)$ & $M(S D)$ & $t$ \\
\hline Age realized sexually attracted to males & $12(2)$ & $12(2)$ & $12(2)$ & -1.5 \\
\hline
\end{tabular}

$* p<0.05 ; * * p<0.01$.

Table 2. Associations Between Guardian Permission Questions and Not Being Out With at Least One Guardian Among 14- to 17-Year-Old Males Who Are Interested in Male Sexual Partners in the United States

\begin{tabular}{|c|c|c|c|c|c|}
\hline \multirow[b]{3}{*}{ Surveys } & Total & Not Out & Out & \multirow[b]{3}{*}{ OR $(95 \%$ CI $)$} & \multirow[b]{3}{*}{$\operatorname{AOR}(95 \% \mathrm{CI})$} \\
\hline & $(N=206)$ & $(n=97)$ & $(n=109)$ & & \\
\hline & $n(\%)$ & $n(\%)$ & $n(\%)$ & & \\
\hline \multicolumn{6}{|l|}{ Current survey } \\
\hline Would not participate if guardian permission was required & $171(83)$ & $87(90)$ & $84(77)$ & $2.6(1.2,5.7)$ & $2.9(1.2,6.8)$ \\
\hline Guardian permission should not be required & $193(94)$ & $92(96)$ & $101(93)$ & $1.8(0.5,6.3)$ & $2.2(0.6,8.0)$ \\
\hline \multicolumn{6}{|l|}{ Future study } \\
\hline Would not participate if guardian permission was required & $179(87)$ & $91(95)$ & $88(81)$ & $4.3(1.5,12.0)$ & $4.8(1.7,13.9)$ \\
\hline Guardian permission should not be required & $202(98)$ & $96(99)$ & $106(97)$ & $2.7(0.3,26.5)$ & $2.3(0.2,24.6)$ \\
\hline
\end{tabular}

Note. AOR adjusted for race/ethnicity, age, and sexual orientation. $\mathrm{CI}=$ confidence interval; $\mathrm{OR}=$ odds ratio; $\mathrm{AOR}=$ adjusted odds ratio.

with a guardian). Participants who were out gave this type of response less often than those who were not out for the future intervention study (current: $27 \%$ versus $46 \%$; future: $10 \%$ versus $44 \%$ ).

\section{Reasons Against Requiring Guardian Permission}

Quantitative data. Most AMSM agreed guardian permission might lead to questions about their sexual behaviors (current: 92\%; future: 91\%) and SEOM use 
Table 3. Associations Between Agreeing With Reasons to Require Guardian Permission and Not Being Out With at Least One Guardian Among 14- to 17-Year-Old Males Who Are Interested in Male Sexual Partners in the United States

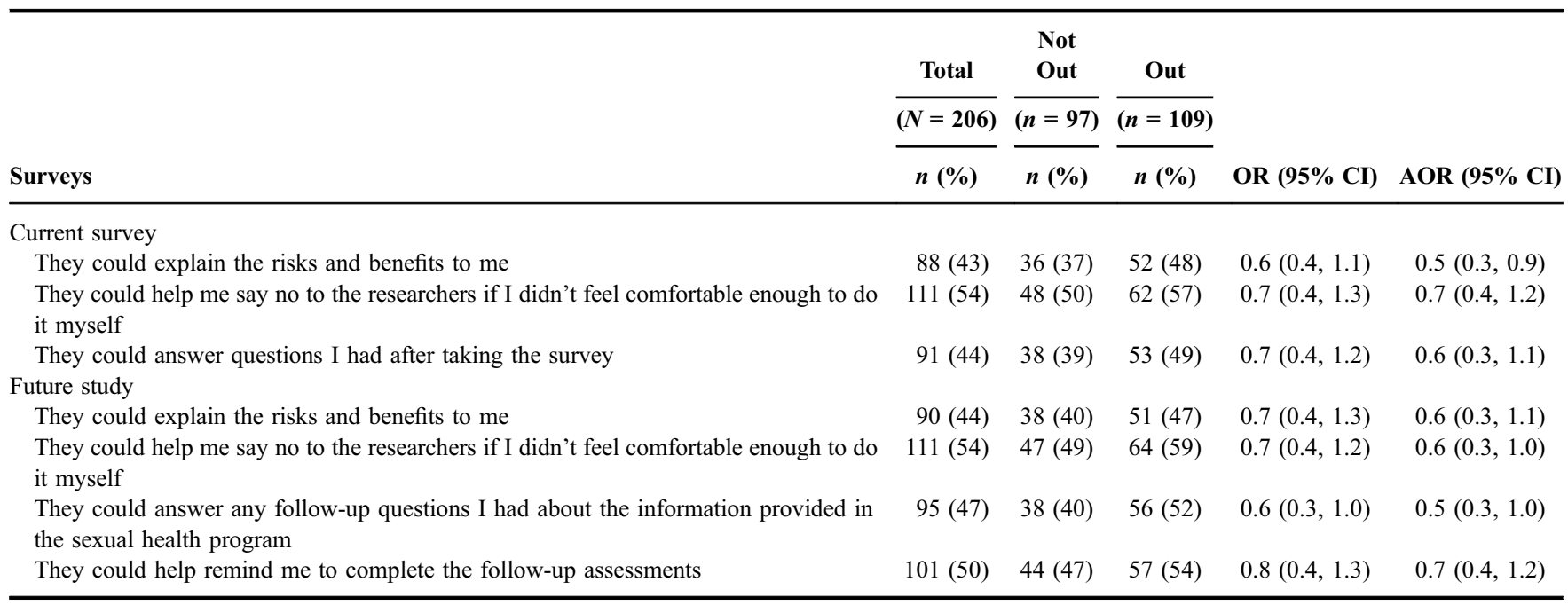

Note. AOR adjusted for race/ethnicity, age, and sexual orientation. $\mathrm{CI}=$ confidence interval; $\mathrm{OR}=$ odds ratio; $\mathrm{AOR}=$ adjusted odds ratio.

Table 4. Associations Between Agreeing With Reasons Against Requiring Guardian Permission and Not Being Out With at Least One Guardian Among 14- to 17-Year-Old Males Who Are Interested in Male Sexual Partners in the United States

\begin{tabular}{|c|c|c|c|c|c|}
\hline \multirow[b]{3}{*}{ Surveys } & Total & Not Out & Out & \multirow[b]{3}{*}{ OR $(95 \%$ CI $)$} & \multirow[b]{3}{*}{$\operatorname{AOR}(95 \% \mathrm{CI})$} \\
\hline & $(N=206)$ & $(n=97)$ & $(n=109)$ & & \\
\hline & $n(\%)$ & $n(\%)$ & $n(\%)$ & & \\
\hline \multicolumn{6}{|l|}{ Current survey } \\
\hline They might punish me & $99(48)$ & $58(60)$ & $41(38)$ & $2.5(1.4,4.4)$ & $2.3(1.3,4.1)$ \\
\hline They might start asking about my sexual behavior & $189(92)$ & $91(94)$ & $97(90)$ & $1.7(0.6,4.8)$ & $1.7(0.6,5.0)$ \\
\hline They might start asking about my pornography use & $183(89)$ & $85(88)$ & $97(90)$ & $0.8(0.3,1.9)$ & $0.7(0.3,1.8)$ \\
\hline They might find out that I am gay, bisexual, or interested in sex with male partners & $164(80)$ & $91(94)$ & $73(68)$ & $7.1(2.8,17.7)$ & $8.9(3.4,23.7)$ \\
\hline They might kick me out of the house & $49(24)$ & $34(35)$ & $15(14)$ & $3.4(1.8,6.8)$ & $3.3(1.6,6.7)$ \\
\hline They might make me talk to a counselor or religious person & $95(46)$ & $54(56)$ & $41(38)$ & $2.1(1.2,3.6)$ & $2.1(1.2,3.9)$ \\
\hline \multicolumn{6}{|l|}{ Future study } \\
\hline They might punish me & $102(50)$ & $62(66)$ & $40(37)$ & $3.3(1.8,5.9)$ & $3.2(1.7,6.0)$ \\
\hline They might start asking me about my sexual behavior & $186(91)$ & $93(98)$ & $93(86)$ & $7.5(1.7,33.7)$ & $7.4(1.5,35.5)$ \\
\hline They might start asking me about pornography use & $182(90)$ & $88(93)$ & $94(87)$ & $1.9(0.7,4.9)$ & $1.7(0.6,4.9)$ \\
\hline They might find out that I am gay, bisexual, or interested in sex with male partners & $157(78)$ & $91(96)$ & $66(62)$ & $13.8(4.7,40.4)$ & $14.8(4.9,45.0)$ \\
\hline They might kick me out of the house & $48(24)$ & $32(34)$ & $16(15)$ & $3.0(1.5,5.9)$ & $2.6(1.3,5.2)$ \\
\hline They might make me talk to a counselor or religious person & $94(47)$ & $53(56)$ & $41(38)$ & $2.0(1.2,3.6)$ & $1.9(1.1,3.5)$ \\
\hline
\end{tabular}

Note. AOR adjusted for race/ethnicity, age, and sexual orientation. $\mathrm{CI}=$ confidence interval; $\mathrm{OR}=$ odds ratio; $\mathrm{AOR}=$ adjusted odds ratio.

(current: $89 \%$; future: $90 \%$ ) or to being outed (current: $80 \%$; future: $78 \%$ ) (Table 4). Compared to participants who were out, those who were not out were more likely to feel that they would be punished (current: AOR $=2.3,95 \%$ CI: 1.3 to 4.1 ; future: $\mathrm{AOR}=3.2,95 \% \mathrm{CI}: 1.7$ to 6.0$)$, outed (current: $\mathrm{AOR}=8.9,95 \%$ CI: 3.4 to 23.7 ; future: $\mathrm{AOR}=14.8,95 \%$ CI: 4.9 to 45.0 ), kicked out of the house (current: $\mathrm{AOR}=3.3,95 \% \mathrm{CI}: 1.6$ to 6.7 ; future: $\mathrm{AOR}=2.6,95 \% \mathrm{CI}: 1.3$ to 5.2$)$, or forced to speak with a counselor/religious person (current: $\mathrm{AOR}=2.1,95 \% \mathrm{CI}$ : 1.2 to 3.9 ; future: $\mathrm{AOR}=1.9,95 \% \mathrm{CI}$ : 1.1 to 3.5 ) if guardian permission was required. Regardless of outness, the majority $(87 \%)$ reported that it would be very easy or easy for them to say no to a researcher if they did not want to participate.

Qualitative data. Of those who responded to the open-ended question asking them to elaborate on other reasons why guardian permission should not be required for the current survey $(n=112)$ or the future study $(n=70)$, the most common reasons given were that (a) requiring guardian permission would be an invasion of privacy (current: $31 \%$; future: $19 \%$ ), (b) it would be uncomfortable (current: 16\%; future: 19\%), and (c) it could be dangerous (current: 22\%; future: 23\%). There 
were no meaningful differences in the frequency of endorsement of these reasons by outness with a guardian.

For responses that highlighted privacy, most participants stated something like the sentiments of two participants: "It's an invasion of privacy" (16 years old, Latino, out with a guardian) and "Sometimes kids like to keep this information to themselves" (17 years old, Black/African American, out with a guardian). Some participants were more nuanced in their language. For example, one participant stated, "It's not their business. It's not their choice. The law should be more considerate to recognize teens as people with rights of privacy too" (15 years old, Black/African American, not out with a guardian). Another stated, "I should have some amount of personal freedom to share my own personal experiences with a researcher without my parents being involved" (14 years old, White, not out with a guardian).

When talking about guardian permission for sexual health research being uncomfortable, participants often noted that they did not want to talk with their guardians about these topics. As one participant said, "I don't talk to my parents about stuff like this because I don't feel comfortable doing it and I feel like I don't have to" (15 years old, White, not out with a guardian). Another stated, "[It] is awkward to discuss with a person who upholds you to a standard of 'innocence,' like being abstinent and heterosexual" (16 years old, Latino, not out with a guardian). Stated another way, "[S]ince these questions are pretty personal, a lot of teens would not feel comfortable with their parents knowing" (15 years old, White, not out with a guardian). Many participants stated sentiments similar to this participant: "It could make people uncomfortable" (14 years old, mixed race/other, not out with a guardian).

Youth felt that requiring guardian permission could be dangerous. One participant stated, "[F]or some people it could be really dangerous for their guardian(s) to find out if they are unsupportive and the participant is dependent on them" (16 years old, White, not out to a guardian); another wrote, "It's not always safe to have parents' permission on a topic like this" (17 years old, mixed race/other, out to a guardian). Some feared consequences to requiring guardian permission. Two responses included: "They could kick me out or punish me" (14 years old, Black/African American, not out to a guardian) and "Because we could be disowned or something" (17 years old, Latino, out to a guardian).

\section{Discussion}

AMSM experience increased risk for HIV acquisition (CDC, 2016) and decreased access to relevant sex education (Raifman et al., 2018; Rasberry et al., 2018). In lieu of relevant sexual education, AMSM turn to the Internet to obtain sexual health information and to locate sexual health-related services (DeHaan, Kuper, Magee, Bigelow, \& Mustanski, 2013; Magee et al., 2012). Although AMSM frequently use the Internet to find sexual health information and locate services, they also recognize that the Internet can be an unreliable source (DeHaan et al., 2013; Magee et al., 2012). Online sexual health interventions for these youth have the potential not only to meet them where they are already seeking sexual health information, but also to help them develop the necessary skills to critically examine the information available online and dispel myths that may be presented (Nelson \& Carey, 2016).

Despite the importance of tailored sexual health interventions for AMSM that address the misinformation they may be receiving online, there has been limited research among AMSM under age 18 to guide the development of interventions for these youth. A barrier to the inclusion of AMSM in sexual health research is the stance that many IRBs take in requiring guardian permission for research involving underage AMSM. Federal regulations permit IRBs to waive guardian permission when research is minimal risk or when such permission is not a reasonable protection for the youth (U.S. Department of Health and Human Services, 2009). The few online sexual health studies that have been conducted with AMSM have received waivers of guardian permission, indicating that waivers of guardian permission can be successfully obtained for this work from some IRBs (Bauermeister et al., 2015; Mustanski, Garofalo, Monahan, Gratzer, \& Andrews, 2013; Mustanski et al., 2015; Ybarra et al., 2017). Empirical evidence on the barriers and potential harms guardian permission poses to online sexual health research among AMSM is essential to making informed judgments regarding the risks and benefits of this requirement (Fisher \& Mustanski, 2014; Mustanski \& Fisher, 2016). To provide IRBs and investigators with the information they need to make ethical decisions around guardian permission for online sexual health research with AMSM, we examined AMSM attitudes toward guardian permission for an online sexual health survey and for a future online sexual health intervention trial.

In this sample, AMSM overwhelmingly reported that they would not have participated in the current survey if guardian permission had been required and would not participate in a future online sexual health intervention study if guardian permission were to be required. This was particularly true for individuals who were not out to their guardian (s); these AMSM were three times more likely to say they would not have participated in the survey and five times more likely to say they would not participate in the intervention study. Further, regardless of outness with a guardian, almost all participants felt that guardian permission should not be required for this type of research. These findings are in line with similar findings that requiring guardian permission would decrease participation in sexuality-focused online survey research, HIV testing studies, and PrEP prevention trials among sexual and gender minority youth (Fisher et al., 2016; Macapagal et al., 2017; Mustanski, Coventry, et al., 2017).

Only about half of the participants agreed with proposed reasons why guardian permission should be required. Previous research regarding HIV testing among sexual and 
gender minority adolescents found that less than $10 \%$ of participants endorsed similar reasons for requiring guardian permission (Mustanski, Coventry, et al., 2017). Measurement difference may explain these two findings. In the HIV testing study, participants were provided a list of potential reasons and asked to "check all that apply" (Mustanski, Coventry, et al., 2017). In the current study, participants indicated how much they agreed or disagreed with each potential reason. Asking participants to indicate agreement may capture more nuanced data about participants' attitudes. Research should examine the best methods for measuring the risks and benefits of guardian permission among AMSM.

Most participants endorsed multiple reasons why guardian permission could be detrimental, including concerns that it would be an invasion of their privacy, lead to unwanted outing, and endanger participants. Participants also felt that requiring guardian permission would lead to uncomfortable conversations with their guardian(s), which could serve as a barrier to participation. These findings supplement the results of previous smaller studies with sexual and gender minority youth that found requiring guardian permission would bias samples and may lead to harm for participants (Fisher et al., 2016; Macapagal et al., 2017; Mustanski, Coventry, et al., 2017).

Guardian permission requirements are predicated on assumptions that guardian decisions reflect the best interest of the child and protect the child from harm, and that youth are incapable of making informed decisions on their own or will have difficulty saying no to researchers. Our results as well as related research indicate that these assumptions may not hold true (Fisher et al., 2016; Macapagal et al., 2017; Mustanski, Coventry, et al., 2017). Specifically, guardians may make decisions based on their own beliefs about sexuality rather than focusing on the risks and benefits of youth participation (Macapagal et al., 2017). Further, requiring guardian permission has the potential to increase risks for some participants, especially for those with guardians who do not support their child's sexual preferences. Research also indicates that adolescents ages 14 and older understand the nature of research and participant rights at the same level as adults (Fisher et al., 2016; Koelch et al., 2009). Finally, our results, in line with previous HIV-specific research (Fisher et al., 2016; Mustanski, Coventry, et al., 2017), found that the majority of adolescents feel capable of declining participation in online sexual health research on their own.

As guardian permission appears to serve as a barrier to participation and may not be necessary to protect AMSM participating in online sexual health research, it is important for researchers and IRBs to consider alternative ways to protect AMSM participating in this critical work. One means to protect these youth is to create a consent process that matches the developmental and educational status of participants (Fisher et al., 2016; Fisher \& Mustanski, 2014; Mustanski \& Fisher, 2016). Research on optimizing consent among youth recommends a process that includes multimedia presentations, quizzes to assess understanding, and an emphasis on the potential benefits of the research for youth (Mustanski, Coventry, et al., 2017; Sineath et al., 2014). Additional research assessing the best way to present online consent materials that are understandable, are engaging, and optimize adolescents' ability to make informed and voluntary participation is warranted.

The limitations of this study should be considered. Although this study presents data from a relatively large and diverse sample, the findings may not generalize to other youth, such as transgender or youth interested exclusively in opposite-sex partners. Further, participants were recruited through advertisements on social media platforms. It is possible that youth who click on an advertisement for a sexual health study differ from youth who do not. As social media Web sites are commonly used for recruiting sexual minority youth (e.g., Mustanski et al., 2015; Ybarra et al., 2017), it is important to assess potential bias that results from these methods. Notably, only 206 (31\%) of the 661 eligible individuals completed the study and were included in the analyses. Differential attrition in this study occurred primarily during the consent process, lending further support regarding the need for effective and efficient online consent processes for sexual health research. Although attrition is not unusual in online research, additional investigation assessing ways to decrease attrition generally and statistical means to address potential biases introduced by attrition in online research is needed (Hochheimer et al., 2016). Lastly, our participants reported on their perceptions of how their guardians would react to their participation in online sexual health research. These assumptions may not accurately reflect how guardians would react. Two U.S. studies found that guardians understand the importance of guardian permission waivers for HIV research and believe that waivers of guardian permission increase study validity and reduce obstacles to participation (Mustanski, Macapagal, et al., 2017; Newcomb, Clifford, Greene, \& Mustanski, 2016). Additional research assessing guardian attitudes toward AMSM participation in online sexual health research and guardian permission requirements, especially among guardians who are less likely to be accepting of their adolescents' sexual preferences, is needed.

In conclusion, AMSM are getting most of their sexual health information from the Internet, likely without guardian permission or awareness. Research on online sexual health interventions for AMSM is critical to ensure the creation of efficacious sexual health programs that provide essential information and increase AMSM's ability to engage in healthy sexual relationships. Requiring guardian permission for this research would likely exclude youth who are not out to their guardians or do not feel comfortable asking for guardian permission. AMSM who are not out or have unsupportive families are at increased risk for adverse health outcomes (Glick \& Golden, 2014; Ryan, Huebner, Diaz, \& Sanchez, 2009). Eliminating these youth from online sexual health research will bias our understanding of their needs, which, in turn, will undermine the development of efficacious online sexual health 
interventions. Among the advantages of conducting online sexual health intervention research with AMSM is the removal of interpersonal, geographic, logistical, and stigma-based barriers to participation (Lane et al., 2015; Mustanski, 2015). Given our results, guardian permission appears to potentially create a significant barrier to the online sexual health research needed to promote sexual well-being and decrease HIV risk among AMSM. Therefore, we recommend that investigators and IRBs reevaluate this practice and consider alternative procedures and policies to facilitate this research with AMSM.

\section{Funding and Acknowledgments}

We would like to thank our research assistant, Jaime Ramirez. Funding for the study came from the National Institute on Drug Abuse (R25 DA031608) and the National Institute of Mental Health (K23 MH109346). The content of this publication is solely the responsibility of the authors and does not represent the official views of the National Institutes of Health.

\section{ORCID}

\author{
Kimberly M. Nelson (D) http://orcid.org/0000-0001-8893- \\ 5764
}

Michael P. Carey (10) http://orcid.org/0000-0003-4652-964X

\section{References}

Arrington-Sanders, R., Harper, G. W., Morgan, A., Ogunbajo, A., Trent, M., \& Fortenberry, J. D. (2015). The role of sexually explicit material in the sexual development of same-sex-attracted Black adolescent males. Archives of Sexual Behavior, 44, 597-608. doi:10.1007/ s10508-014-0416-x

Bauermeister, J. A., Pingel, E. S., Jadwin-Cakmak, L., Harper, G. W., Horvath, K., Weiss, G., \& Dittus, P. (2015). Acceptability and preliminary efficacy of a tailored online HIV/STI testing intervention for young men who have sex with men: The Get Connected! program. AIDS and Behavior, 19, 1860-1874. doi:10.1007/s10461-015-1009-y

Bowen, A. M., Daniel, C. M., Williams, M. L., \& Baird, G. L. (2008). Identifying multiple submissions in Internet research: Preserving data integrity. AIDS and Behavior, 12, 964-973. doi:10.1007/s10461-0079352-2

Centers for Disease Control and Prevention. (2016). HIV Surveillance Report, 2015; vol 27. Atlanta, GA: Author. Retrieved from http:// www.cdc.gov/hiv/library/reports/hiv-surveillance.html

DeHaan, S., Kuper, L. E., Magee, J. C., Bigelow, L., \& Mustanski, B. S. (2013). The interplay between online and offline explorations of identity, relationships, and sex: A mixed-methods study with LGBT youth. Journal of Sex Research, 50, 421-434. doi:10.1080/ 00224499.2012.661489

Dunn, L. B., \& Jeste, D. V. (2001). Enhancing informed consent for research and treatment. Neuropsychopharmacology, 24, 595-607. doi:10.1016/S0893-133X(00)00218-9

Fisher, C. B., Arbeit, M. R., Dumont, M. S., Macapagal, K., \& Mustanski, B. (2016). Self-consent for HIV prevention research involving sexual and gender minority youth: Reducing barriers through evidence-based ethics. Journal of Empirical Research on Human Research Ethics, 11, 3-14. doi:10.1177/1556264616633963

Fisher, C. B., \& Mustanski, B. (2014). Reducing health disparities and enhancing the responsible conduct of research involving LGBT youth. Hastings Center Report, 44, S28-S31. doi:10.1002/hast.367

Glick, S. N., \& Golden, M. R. (2014). Early male partnership patterns, social support, and sexual risk behavior among young men who have sex with men. AIDS and Behavior, 18, 1466-1475. doi:10.1007/ s10461-013-0678-7

Green, J., \& Thorogood, N. (2013). Qualitative methods for health research (3rd ed.). Thousand Oaks, CA: SAGE Publications Ltd.

Harris, P. A., Taylor, R., Thielke, R., Payne, J., Gonzalez, N., \& Conde, J. G. (2009). Research electronic data capture (REDCap)-A metadatadriven methodology and workflow process for providing translational research informatics support. Journal of Biomedical Informatics, 42, 377-381. doi:10.1016/j.jbi.2008.08.010

Hergenrather, K. C., Emmanuel, D., Durant, S., \& Rhodes, S. D. (2016). Enhancing HIV prevention among young men who have sex with men: A systematic review of HIV behavioral interventions for young gay and bisexual men. AIDS Education and Prevention, 28, 252-271. doi:10.1521/aeap.2016.28.3.252

Hochheimer, C. J., Sabo, R. T., Krist, A. H., Day, T., Cyrus, J., \& Woolf, S. H. (2016). Methods for evaluating respondent attrition in Web-based surveys. Journal of Medical Internet Research, 18, e301. doi:10.2196/ jmir.6342

Kann, L., Olsen, E. O., McManus, T., Harris, W. A., Shanklin, S. L., Flint, K. H., ... Zaza, S. (2016). Sexual identity, sex of sexual contacts, and health-related behaviors among students in grades 9-12 - United States and selected sites, 2015. Morbidity and Mortality Weekly Report. Surveillance Summaries, 65, 1-202. doi:10.15585/mmwr.ss6509a1

Koelch, M., Singer, H., Prestel, A., Burkert, J., Schulze, U., \& Fegert, J. M. (2009). “. . because I am something special" or "I think I will be something like a guinea pig": Information and assent of legal minors in clinical trials - Assessment of understanding, appreciation and reasoning. Child and Adolescent Psychiatry and Mental Health, 3, 2. doi:10.1186/1753-2000-3-2

Kubicek, K., Beyer, W. J., Weiss, G., Iverson, E., \& Kipke, M. D. (2010). the dark: Young men's stories of sexual initiation in the absence of relevant sexual health information. Health Education \& Behavior, 37, 243-263. doi:10.1177/1090198109339993

Lane, T. S., Armin, J., \& Gordon, J. S. (2015). Online recruitment methods for web-based and mobile health studies: A review of the literature. Journal of Medical Internet Research, 17(7), e183. doi:10.2196/ jmir.4359

Macapagal, K., Coventry, R., Arbeit, M. R., Fisher, C. B., \& Mustanski, B. (2017). "I won't out myself just to do a survey": Sexual and gender minority adolescents' perspectives on the risks and benefits of sex research. Archives of Sexual Behavior, 46, 1393-1409. doi:10.1007/ s10508-016-0784-5

Magee, J. C., Bigelow, L., Dehaan, S., \& Mustanski, B. S. (2012). Sexual health information seeking online: A mixed-methods study among lesbian, gay, bisexual, and transgender young people. Health Education \& Behavior, 39, 276-289. doi:10.1177/1090198111401384

McHugh, M. L. (2012). Interrater reliability: The kappa statistic. Biochemia Medica, 22, 276-282. doi:10.11613/issn.1846-7482

Mustanski, B. (2011). Ethical and regulatory issues with conducting sexuality research with LGBT adolescents: A call to action for a scientifically informed approach. Archives of Sexual Behavior, 40, 673-686. doi:10.1007/s10508-011-9745-1

Mustanski, B. (2015). Future directions in research on sexual minority adolescent mental, behavioral, and sexual health. Journal of Clinical Child \& Adolescent Psychology, 44, 204-219. doi:10.1080/15374416.2014.982756

Mustanski, B., Coventry, R., Macapagal, K., Arbeit, M. R., \& Fisher, C. B. (2017). Sexual and gender minority adolescents' views on HIV research participation and parental permission: A mixed-methods study. Perspectives on Sexual and Reproductive Health, 49, 111121. doi: $10.1363 /$ psrh. 12027 


\section{GUARDIAN PERMISSION FOR ADOLESCENT MALES INTERESTED IN SEX WITH MALES SEX RESEARCH}

Mustanski, B., \& Fisher, C. B. (2016). HIV rates are increasing in gay/ bisexual teens: IRB barriers to research must be resolved to bend the curve. American Journal of Preventive Medicine, 51, 249-252. doi:10.1016/j.amepre.2016.02.026

Mustanski, B., Garofalo, R., Monahan, C., Gratzer, B., \& Andrews, R. (2013). Feasibility, acceptability, and preliminary efficacy of an online HIV prevention program for diverse young men who have sex with men: The Keep It Up! Intervention. AIDS and Behavior, 17, 29993012. doi:10.1007/s10461-013-0507-z

Mustanski, B., Greene, G. J., Ryan, D., \& Whitton, S. W. (2015). Feasibility, acceptability, and initial efficacy of an online sexual health promotion program for LGBT youth: The Queer Sex Ed intervention. Journal of Sex Research, 52, 220-230. doi:10.1080/00224499.2013.867924

Mustanski, B., Lyons, T., \& Garcia, S. C. (2011). Internet use and sexual health of young men who have sex with men: A mixed-methods study. Archives of Sexual Behavior, 40, 289-300. doi:10.1007/s10508-009-9596-1

Mustanski, B., Macapagal, K., Thomann, M., Feinstein, B. A., Newcomb, M. E., Motley, D., \& Fisher, C. B. (2017). Parents' perspectives about adolescent boys' involvement in biomedical HIV prevention research. Archives of Sexual Behavior. doi:10.1007/s10508-017-1035-0

Nelson, K. M., \& Carey, M. P. (2016). Media literacy is an essential component of HIV prevention for young men who have sex with men. Archives of Sexual Behavior, 45, 787-788. doi:10.1007/ s10508-016-0712-8

Newcomb, M. E., Clifford, A., Greene, G. J., \& Mustanski, B. (2016). Parent perspectives about sexual minority adolescent participation in research and requirements of parental permission. The Journal of Adolescent Health, 59, 443-449. doi:10.1016/j.jadohealth.2016.05.014

Newcomb, M. E., \& Mustanski, B. (2014). Diaries for observation or intervention of health behaviors: Factors that predict reactivity in a sexual diary study of men who have sex with men. Annals of Behavioral Medicine, 47, 325-334. doi:10.1007/s12160-013-9549-8

NVivo qualitative data analysis software. (2012). (Version 10). Melbourne, Australia: QSR International Pty Ltd.

Raifman, J., Beyrer, C., \& Arrington-Sanders, R. (2018). HIV education and sexual risk behaviors among young men who have sex with men. LGBT Health, 5, 131-138. doi:10.1089/lgbt.2017.0076
Rasberry, C. N., Condron, D. S., Lesesne, C. A., Hocevar Adkins, S., Sheremenko, G., \& Kroupa, E. (2018). Associations between sexual risk-related behaviors and school-based education on HIV and condom use for adolescent sexual minority males and their non-sexual-minority peers. LGBT Health, 5, 69-77. doi:10.1089/lgbt.2017.0111

Ryan, C., Huebner, D., Diaz, R. M., \& Sanchez, J. (2009). Family rejection as a predictor of negative health outcomes in White and Latino lesbian, gay, and bisexual young adults. Pediatrics, 123, 346-352. doi:10.1542/peds.2007-3524

Sineath, R. C., Ross, A., Sullivan, P. S., Stephenson, R., Sanchez, T., \& Stein, A. D. (2014). Methods for improving consent and survey completion in online HIV prevention research with young men who have sex with men. Presented at the Medicine 2.0 Conference. Retrieved from http://www.medicine20congress.com/ocs/index.php/ med/med2014/article/view/2671

Sullivan, P. S., Grey, J. A., \& Simon Rosser, B. R. (2013). Emerging technologies for HIV prevention for MSM: What we have learned, and ways forward. Journal of Acquired Immune Deficiency Syndromes, 63, S102-107. doi:10.1097/QAI.0b013e3182949e85

U.S. Department of Commerce Economics and Statistics Administration. (2015). Census regions and divisions of the United States. Washington, DC: U.S. Census Bureau. Retrieved from https://www2. census.gov/geo/pdfs/maps-data/maps/reference/us_regdiv.pdf

U.S. Department of Health and Human Services. (2009, January 15). 45 CFR 46 [Text]. Retrieved February 7, 2018, from https://www.hhs. gov/ohrp/regulations-and-policy/regulations/45-cfr-46/index.html

The University of California at San Diego Task Force on Decisional Capacity. (2003). Procedures for determination of decisional capacity in persons participating in research protocols. San Diego, CA: The University of California.

University of North Dakota Center for Rural Health. (2014, August 4). RUCA 3.10. Retrieved July 7, 2017, from https://ruralhealth.und.edu/ ruca

Ybarra, M. L., Prescott, T. L., Phillips, G. L., Bull, S. S., Parsons, J. T., \& Mustanski, B. (2017). Pilot RCT results of an mHealth HIV prevention program for sexual minority male adolescents. Pediatrics, 140, e20162999. doi:10.1542/peds.2016-2999 